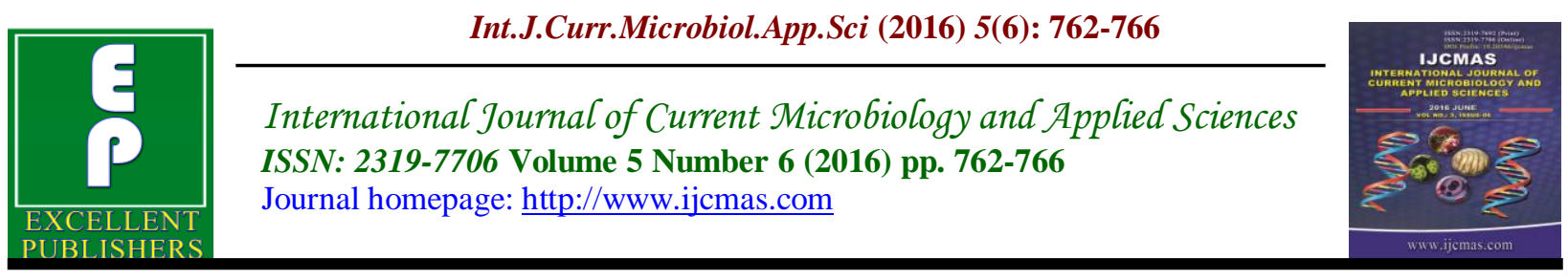

Original Research Article

http://dx.doi.org/10.20546/ijcmas.2016.506.082

\title{
Oral Microbial Pattern in Children with Decayed Teeth
}

Anila Prabil ${ }^{*}$ and Pratibha Dalal ${ }^{2}$
Terna Medical College, Sector 12, Nerul (W), Navi Mumbai, India
*Corresponding author

\section{Introduction}

Despite great improvements in the global oral health status, dental caries still remains one of the most prevalent diseases particularly in children where it is the primary source of tooth loss. Caries is a chronic disease that progresses slowly and is characterized by localized and irreversible destruction of the tooth (Van GemertSchricks, 2008) People with disabilities and lower socioeconomic status suffer from the highest prevalence and pathogenicity of dental caries. S. mutans and Candida albicans are the two microbes often implicated in oral diseases. Caries results from the complex interactions among the microbial species adhering to the tooth surface, with dietary, salivary, and genetic influences. The metabolic microbial interactions that take place in the dental biofilm result in acid production and extracellular glucan formation which promote microbial attachment to teeth. The recognition of acid as the central etiological agent in dental caries initiated a search for the causative microorganisms in the oral microbiota, and in the early 1960s, the 
bacterial species Streptococcus mutans $(S$. mutans) became the main focus of caries research, and assumed to be the specific cariogen (Kouidhi et al., 2010). During the stage of invasion, $S$. mutans coadhere or coaggregate with other microbial species, followed by proliferation and spread into other sites in the oral mucosa modulated by concerted action of genes and signaling molecules. In the final stage, the biofilm reaches a steady state which changes the equilibrium balance of the oral ecology; as a result, bacteria gain access into the deeper tissues and recesses in the gingival areas, ultimately causing dissolution of hydroxyapatite crystals in enamel and dentin which results in cavitation within the tooth (Rouabhia et al., 2012). If not prevented, this cavitation provides an ecological niche where microorganisms form a protected biofilm, enabling caries to progress gradually. It has been accepted for decades that $S$. mutans is the etiologic agent of dental caries but recent evidence indicates $S$. mutans association with fungal pathogen Candida albicans $(C$. albicans) mediate cariogenic development (Barbieri et al., 2007; Jarosz et al., 2009).

The ability of $C$. albicans to switch its morphology between yeast and hyphal forms contributes to its pathogenesis. In the oral cavity, the coadhesion between $C$. albicans and oral bacteria is crucial for $C$. albicans colonization and persistence. In addition to providing adhesion sites, the streptococci excrete lactate that can act as a carbon source for yeast growth, which in turn reduces oxygen tension to levels preferred by streptococci and provide growth stimulatory factors for the bacteria. The hypothesis of the association between $S$. mutans and C. albicans is based on their mechanisms of virulence and biochemical characteristics as well as host factors that provide a buccal environment favoring the action of both microorganisms (Rouabhia et al., 2012). In fact, several in vitro studies have shown that $C$. albicans enhance the adherence of $S$. mutans, indicating a possible facilitation mechanism during their association where the yeast cells could be used by the bacteria as support for adherence.

\section{Materials}

\section{Source of Data}

The present study was conducted on institutionalized children with special health care needs in Navi Mumbai in association with Terna Dental College in 2012- 2013.

\section{Inclusion Criteria}

Handicapped children attending special school.

Mentally retarded patient having IQ below 70.

Oral health care provided by parent or guardian.

\section{Exclusion Criteria}

Children without parent or guardian consent.

\section{Method}

158 patients in the age group of 5-14years were included in this study. Written informed consent was obtained from at least one of their parents or legal guardians, before enrolment in the study. Participants were individuals institutionalized in an institution for Down's syndrome, Autism, Cerebral palsy, mental retardation, and hearing impairment.

Samples were collected from buccal cavity using a sterile swab. Immediately after sample collection, the swab was placed in a 
sterile tube containing $1 \mathrm{ml}$ phosphate buffer saline and tubes were transported to microbiology laboratory for further analysis. These samples were then sub- cultured on agar plate containing Mitis Salivaris Bacitracin (MSB) agar and Blood agar. The plates were incubated aerobically at $37^{\circ} \mathrm{C}$ overnight. Organisms were identified according to the CLSI guidelines standards. The biotype identification of the Strep.mutans was based on the fermentation of sugars - mannitol and sorbitol. Those samples which had growth on blood agar, gram smears were made from all these samples and necessary biochemical tests were carried out for species identification.

\section{Results and Discussion}

Children fulfilling the criteria of inclusion in the study were enrolled for the study.

1. Out of 158 samples 147 samples yielded positive growth on blood agar \% of samples that showed positivity $-93.03 \%$

2. Growth on MSB - 108 (73.4\%)

3. Samples positive for sugar fermentation test mannitol and sorbitol - $108(100 \%)$

Number of samples that showed growth on blood agar was $-147(93.03 \%)$. Others did not show any growth probably because they were anaerobes which were not part of our study. Various organisms grown on blood agar in our study were - Streptococcus mutans(73.4\%),Candida(62.58\%), Other Streptococcus $\operatorname{spp}(26.53 \%)$, Staphylococcus aureus (19.04\% )and Coagulase negative staphylococcus $(8.16 \%)$.

In our study Streptococcus mutans is the most common organism isolated in children with dental caries followed by Candida albicans and Staphylococcus aureus (19.04 $\%$ ). This study supports the study of Hassan-
Olajokun et al., in which they found S.mutans as the commonest causes of caries followed by lactobacillus and then Staphylococcus aureus. Mannitol and sorbitol sugar fermentation test was positive for all suspected organism that were grown on MSB.

$62.58 \%$ of samples yielded growth of Candida albicans. It is by far the fungal species most commonly isolated from infected root canals, showing resistance to intercanal medication Study by Evandro Leao Ribeiro shows that in children with Down's syndrome, $87.5 \%$ of Candida albicans were isolated, which is more than our study.

Staphylococcus aureus $28(19.04 \%)$ were isolated in our study which is major human pathogen, responsible for a number of hospital-acquired infections, initially colonizes several locations in the human body, but the mouth and hands are the main reservoirs for propagation of this pathogen in the hospital environment. Staphylococcus aureus is a putative pathogen of many oral diseases, such as oral mucositis (Gibson et al., 2000), periodontitis (Passariello et al., 2012), peri-implantitis (Heitz-Mayfield \& Lang, 2010), endodontic infections (Poeschl et al., 2011) and even dental caries (Kouidhi et al., 2010).

Isolation of Coagulase negative Staphylococcus in our study was 8.16 $\%$.This rate is lower than the study done by Alicia I et al., in 2010. These are usually regular colonizers of the oral cavity, which can act as a reservoir for the dissemination of infection. The ability of Staphylococcus spp and Candida spp to form a biofilm and live within certain niches allows them to develop mechanisms that increase persistence, such as the evasion of host defenses. 
Table.1 Depicts the organisms isolated on blood agar

\begin{tabular}{|l|l|l|}
\hline \multicolumn{1}{|c|}{ Organisms } & \multicolumn{1}{|c|}{ Number } & \multicolumn{1}{|c|}{$\begin{array}{c}\text { Percentage } \\
(\%)\end{array}$} \\
\hline S.mutans & 108 & 73.4 \\
\hline Candida & 92 & 62.58 \\
\hline $\begin{array}{l}\text { Other streptococcus } \\
\text { spp }\end{array}$ & 39 & 26.53 \\
\hline $\begin{array}{l}\text { Staphylococcus } \\
\text { aureus }\end{array}$ & 28 & 19.04 \\
\hline $\begin{array}{l}\text { Coagulase negative } \\
\text { staphylococcus }\end{array}$ & 12 & 8.16 \\
\hline
\end{tabular}

In conclusion, presence of $C$. albicans in the oral environment can now be considered an additional factor that needs to be taken into account in evaluating caries risk. All organisms that grew on Mitis Salivarius Bacitracin agar were S.mutans and so it can be concluded that the MSB is an ideal medium for isolation of S.mutans .

S. mutans and Candida albicans are the two microbes often implicated in oral diseases. However few more studies are needed to know if Candida and S.aureus are only oral carriage or have cariogenic potential as much as S.mutans. However, such studies are important as a base to develop preventive programs and to assess their success. Effective toothbrush use requires a level of manual dexterity, tactile acuity which has likely diminished in children with special care needs, and requires others. This could be one of the reason for caries in these children. Motivation of care takers need to be reinforced.

\section{Acknowledgement}

Dr.Bhavesh Raut -Terna dental college.

\section{References}

Akdeniz, B.G., Koparal, E., Sen, B.H., Ates, M., Denizci, A.A. 2002. Prevalence of
Candida albicans in oral cavities and roots canals of children. ASDC J. Dent. Child., 69: 289-292.

Barbieri DdS'AV, Vicente, V.A., Fraiz, F.C., Lavoranti, O.J., Svidzinski, T.I.E., et al. 2007. Analysis of the in vitro adherence of Streprococcus mutans and Candida albicans. Braz. J. Microbiol., 38: 624-663. doi: 10.1590/s1517-83822007000400 009

Bergey's Manual of Determinative Bacteriology (9th ed., 1994)

Brogden, K.M., Guthmiller, J.M., editors 2008. Polymicrobial diseases. Washington: ASM Press.

Calderone, R.A., editor. 2012. Candida and Candidiasis. Washington: ASM Press.

Fingold, S. and Baron, E. (1986). Method of identification of etiologic agent of infection disease. In: "Bailey and Scotts diagnostic microbiology". 7th edt. C. V. Mosby; C. St. Louis. P: 382

Hassan-Olajokun, R.E., Folarin, A.A., Olaniran, O., Umo, A.N. Afr. J. Cln. Exper. Microbiol., 9(2): 103 - 108. The prevalent bacterial isolates of dental caries in school age children attending the dental clinic.

Isalm, B.K.S., Khan, A.U. 2007. Dental caries: from infection to prevention. Med. Sci. Monit., 13: RA196-203.

Jarosz, L.M., Deng, D.M., van der Mei, H.C., Crielaard, W., Krom, B.P. 
2009. Streptococcus mutans competence-stimulating peptide inhibits Candida albicans hypha formation. Eukaryotic Cell, 8: 16581664. doi: 10.1128/ec.00070-09

Klinke, T., Kneist, S., de Soet, J.J., Kuhlisch, E., Mauersberger, S., et al. 2009. Acid production by oral strains of Candida albicans and lactobacilli. Caries Res, 43: 83-91. doi: 10.1159/000204911

Kouidhi, B., Zmantar, T., Hentati, H., Bakhrouf, A. 2010. Cell surface hydrophobicity, biofilm formation, adhesives properties and molecular detection of adhesins genes in Staphylococcus aureus associated to dental caries. Microb. Pathog., 49: 1422.

Lowy, F.D. Staphylococcus aureus infections. N. Engl. J. Med., 339(8): 520-32.

Martinez-Mier, E.A., Ferrera-Zandona, A., Ando, M,. Gonzalez-Cabezas, C., et al. 2009. Zero DTFM, The biology, prevention, diagnosis and treatment of dental caries. JADA, 140: 25S-34S. doi: 10.14219/jada.archive.2009.0355

Matee, M.I., Mikx, F.H., Maselle, S.Y., Van Palestein Helderman, W.H. 1992. Mutans streptococci and lactobacilli in breast-fed children with rampant caries. Caries Res., 26: 183-7.

Raja, M., Hannan, A., Ali, K. 2010. Association of oral candidal carriage with dental caries in children. Caries Res., 44: 272-276. doi: $10.1159 / 000314675$

Rouabhia, M., Chmielewski, W. 2012. Diseases associated with oral polymicrobial biofilms. Open Mycol. J., 6: 27-32. $\quad$ doi: $10.2174 / 1874437001206010027$

Van Gemert-Schricks, M.C.M., van Amerongen, W.E., ten Cate, J.M., Aartman, I.H.A. 2006. The effect of different treatment strategies on the oral health of children: a longitudinal randomized controlled trial. Clin Oral Invest., 12: 361-8.

\section{How to cite this article:}

Anila Prabil and Pratibha Dalal. 2016. Oral Microbial Pattern in Children with Decayed Teeth. Int.J.Curr.Microbiol.App.Sci. 5(6): 762-766. doi: http://dx.doi.org/10.20546/ijcmas.2016.506.082 